\title{
Choice Is Empowering: Getting Strategic About Preventing HIV Infection in Women
}

Since the late 1980s and early 1990s, we have come a considerable distance in recognizing that successful HIV prevention work among women means the adoption of a woman-centered paradigm, one that is grounded in women's realities and acknowledges gender roles and gender-based power differentials as critical factors in women's ability to make and effect decisions regarding their health and welfare. We have learned that most women around the world cannot control male condom use, and we have begun to understand that women's attitudes toward and use of protective methods are based on personal, relational, sociocultural and structural factors, with a different mix for each woman. HIV prevention has required us to work on two levels: to achieve long-term, structural change in women's status, and to provide women with tools for protection over the short term. ${ }^{1}$

We have now recognized the limits of a sole dependence on the male condom. Although this device is highly effective against sexually transmitted pathogens when used correctly and consistently, male control over the male condom undermines its real-world impact. As a result, large-scale male condom campaigns over the first two decades of the HIV epidemic have been inadequate as a public health strategy. Recent studies of U.S. women at high HIV risk show that the proportion of protected sex acts rarely exceeds 15\%, a statistic that has not changed over the past decade. ${ }^{2}$ Women in developing countries are often not protected at all.

Even if a woman's partner agrees to use male condoms, decades of experience from the field of family planning have demonstrated the need for multiple options. We have been operating under the collective illusion that in the case of HIV prevention, this would not be the case.

Our stubborn insistence on presenting the male condom as a "100\% method" has played right into the hands of those who argue that advocating male condom use to prevent HIV infection underserves women because it exposes them to (occasional) failures and does not make the most of women's "power" in saying no to sex. We have seen the credibility of the male condom damaged over the past several years by disinformation campaigns, and the language of reproductive rights twisted to disempower women. Precious resources that could have been used for prevention are now being wasted in countering these attacks. Future HIV prevention efforts should focus on the potential for a given method, program or policy to increase a woman's ability to control her reproductive health, rather than on product efficacy values that apply to a narrow set of users under highly manipulated conditions.

\section{Woman-Controlled Methods}

Long years of advocacy have brought about funding for research on other methods over which women have greater control. The female condom is FDA-approved for the prevention of pregnancy and STIs (including HIV), and is considered to be as efficacious as the male condom. ${ }^{3}$ Although spermicides have been found useless against HIV (and potentially harmful with repeated daily applications ${ }^{4}$ ), cervical barriers hold great promise as risk-reduction tools; the cervix is considered to be vastly more susceptible to HIV infection than the vagina. This susceptibility stems from the greater fragility of the cervical epithelium, as well as the presence of CD4 cells and important HIV co-receptor molecules that are rarely found in the vagina. In addition, the muscular contractions of the cervix aid the flow of fluidsincluding any infectious organisms that are presentupward toward the uterus, fallopian tubes and ovaries. ${ }^{5}$ In recognition of this, a large trial is being conducted to test the effectiveness of a one-size-fits-many diaphragm. ${ }^{6} \mathrm{~A}$ bona fide research platform on microbicides-chemical products applied in the vagina or rectum to prevent HIV acquisitionhas also been established, with Phase III clinical testing on five compounds under way to examine efficacy and safety; the first results are expected in 2007-2008. ${ }^{7}$

\section{Sexual Risk Reduction}

Within the HIV prevention field, widening our approach to include more than the exclusive promotion of the male condom means grasping the essential notion that no prevention method will ever be ideal for all women or in all situations. We are still wrestling with the outdated question of "which is better?" rather than the considerably more constructive and expedient framework of "more is better."

A more efficient next step would be to adopt a sexual risk reduction philosophy, similar to that of the harm reduction approach to needle-related HIV risk among injection drug users. The basic idea behind sexual risk reduction is to give prevention choices-behavioral (such as reducing the number of partners), product-based (such as alternatives to the male condom) or both-to maximize prevention potential. Mathematical modeling exercises have long made it clear that even small increases in access to, and use of, such available methods as the female condom could boost protection against HIV and STIs more than the continued sole emphasis on the male condom. ${ }^{8}$ Harm reduction approaches, notably syringe exchange programs, have played an important role in reducing HIV infections among injection drug users. ${ }^{9}$ Although successful treatment for
By Erica L. Gollub

Erica L. Gollub is visiting professor of epidemiology, INSERM, U593, and Université Victor Segalen Bordeaux 2, Institut de Santé Publique, d'Épidémiologie et de Développement, Bordeaux, France. She was a consultant to the Female Health Company at the time this viewpoint was drafted. 
addiction would be the most efficacious anti-HIV intervention possible, it is clearly not a realistic goal for the vast majority of injection drug users in the short term-just as $100 \%$ condom use has proven to be unachievable over the past 15 years. As part of harm reduction counseling for needle-based HIV risk, users are urged to use clean needles to inject drugs, and, if that is not possible, to avoid sharing needles. The absolute bottom line-and arguably the most controversial formulation of such an approach-is that when it comes to practicing prevention, something is better than nothing. Such a change in strategy is long overdue in our approach to prevention of sexually transmitted HIV in women.

\section{Maximizing Prevention Possibilities for Women}

In the early 1990s, Rosenberg and colleagues showed that female barrier methods such as the diaphragm, with inherently inferior anti-STI efficacy, could nevertheless have great individual or public health value if they were used consistently. ${ }^{10}$ In a review of data from 10 observational trials on the prevention of STIs among populations of women who used male condoms, diaphragms and spermicides, the estimated mean level of condom effectiveness ranged from $30 \%$ to $60 \%$, whereas the estimated mean for spermicide and diaphragm effectiveness ranged from $50 \%$ to $75 \% .{ }^{11}$ Urging the use of any and all available methods that might reduce the risk of HIV and other STIs when male condoms are not used became the official policy of the New York State AIDS Institute in 1992. The institute's policy, "Methods of Personal Protection for Women to Reduce Transmission of HIV Through Vaginal Intercourse,"12 advocated a hierarchical counseling approach that presents available methods that have the potential to reduce STIs and HIV infection, ordered by their efficacy (known or estimated, based on available data). Today, such a hierarchy might place female and male condoms at the top rung, diaphragms and cervical caps on the second rung, and coitus interruptus on the third rung. Quality hierarchical counseling includes urging women to use condoms whenever possible, with discussion of possible strategies. Information is then given, in order, about the other options. A key ingredient is information in plain language about how HIV infects women-i.e., why condoms are the best protection. The beauty of such an approach is that it expedites information-sharing with the women who need it, and that new evidence can change the list itself, the order of methods and the counseling scripts. The policy makes no excuses for the state of scientific knowledge, and does not try to disguise it in any way; the information gaps are honestly and thoroughly disclosed.

A great deal has been learned regarding women's reactions to the hierarchical counseling approach and about the preparation and setting required for its success. ${ }^{13}$ Yet, instead of using available research to maximize coverage, the HIV and AIDS prevention field has, for over a decade, been split on the worth of promoting "partially effective" or imperfect methods.
Some opponents argue that women should be offered only "the best" in prevention methods and that giving information on less efficacious methods is doing them a disservice. According to this reasoning, providing women with information on a menu of prevention methods assumes that they will not use male condoms. For example, a common argument against promotion of the highly effective female condom is that it is appropriate for, or acceptable to, a very small percentage of the world's population and thus a far cry from ideal. ${ }^{14}$ Other opponents argue that hierarchical messages are just too confusing to women-given so many choices, women might opt to use lower-efficacy methods under the assumption that they were protected at the same level as with a condom. There is an implicit notion behind these arguments that what we are doing when we offer women more choices in protection is tempting them to move down from some imagined high level of protection they have at the outset.

As counselors, health providers and educators working in communities of at-risk women every day know only too well, however, a woman at high risk of STIs and HIV infection begins at the level of no protection, or almost no protection, and works up. Each added method amounts to a building block-raising and solidifying the wall that protects her from disease. In research settings, although a few women counseled on and given access to a prevention hierarchy have reported the feared migration away from the male condom, the overwhelming effect is a substantial increase in population protection caused by the adding-on of methods (for example, male condoms alternating with female condoms or male condoms used with diaphragms and spermicide) that more than offsets this effect. ${ }^{15}$ The vast majority of women who do use less effective methods, such as the diaphragm alone, do so in place of using nothing. ${ }^{16}$ The evidence from research on such programs indicates that women respond positively to the notion of choice and can digest complex messages, especially when they are delivered through high-quality counseling. The feeling of having options is liberating and empowering. ${ }^{17}$ Women so counseled, regardless of educational background, social class and race, feel more confident about themselves, their bodies and their right to protection. ${ }^{18}$ They combine methods to arrive at the highest level of protection possible in their circumstances. ${ }^{19}$

Indeed, the patronizing quality of arguments against hierarchical counseling-with their implication that women can handle only simple prevention advice-harkens back to an era predating the consumer's right-to-know and women's health movements in the United States. The solution to a lack of perfect and simple choices is not to withhold information about the options that do exist. This is certainly not an approach that women at high risk of infection would elect for themselves. ${ }^{20}$ Instead of the public health community worrying about insulting, demeaning and confusing women with too many choices, why don't we just "tell it like it is" to the women who desperately need protection, and let them decide? 


\section{Rethinking Available Methods}

At the Microbicides 2004 meeting, a colleague confided to me, "I was wrong about the female condom." He recalled with regret the numerous occasions on which he had belittled the device when it first appeared, in some cases to large audiences. We spoke about how each new method for women's HIV prevention would be imperfect; would appeal to different subgroups of women; would require a similar process of demystification, orientation and training; and would have efficacy levels far less than 100\% (the first microbicides are likely to be $30-50 \%$ efficacious). We noted that women would need to become comfortable with touching their genitals to apply any method. He observed, "The female condom is a method we have here, now!"

Although the Microbicides 2006 meeting revealed more recognition that compounds in development, like their predecessors, will yield imperfect products, there was still no clear consensus on the need for a common platform firmly endorsing research and promotion of all available HIV risk-reduction methods for women. The recent International AIDS Conference emphasized the fundamental role of prevention in the public health response to the epidemic; nevertheless, blanket statements marginalizing the female condom as not useful since all women would not use them (or dismissing them in the same breath as male condoms, as though the dynamic of male control were the same for both devices) were still in evidence. Fourteen years after the New York AIDS Institute led the way with "Methods of Personal Protection for Women to Reduce Transmission of HIV Through Vaginal Intercourse," this policy is still a radical idea.

\section{What It Will Take}

What will it take for us to change our HIV prevention paradigm and welcome the concept of choices for women? In large measure, this will involve individual and institutional soul-searching and the courage to recognize the empirical failure of such notions as the existence of a "100\% method." The field of HIV prevention, armed with the evidence, needs to send a clear message to women that there is no magic bullet for HIV prevention. And we need to do it now.

By energetically endorsing the female condom, we could be reducing STIs and HIV infections as we speak. The undermining of this valuable protection device has worked to the detriment of women. By providing clear, easy-tounderstand information, with visual aids, about the genitals and reproductive organs along with counseling on the female condom, ${ }^{21}$ we could greatly enrich HIV prevention services. Our experience with prevention hierarchies so far suggests numerous activities we could begin now that could lay the foundation for the public health rollout of future women-controlled methods such as microbicides. One such activity would be the refinement of a common counseling script for potential users that could be adapted and replicated in varied settings. Another is the dissemination of a basic provider training manual that directly addresses gen- der issues, sexuality education, provider bias, counseling methods and more. A third is the establishment of a clearinghouse for provider and user training materials for more rapid and effective uptake into newly established country programs. Working from the base of what we have already learned, we could achieve a substantial public health impact with existing technologies like the female condom and lay the foundation for a more rapid uptake of future technologies.

Our inaction has led to a disappointing level of collaboration in the field among different product camps. Research on new woman-initiated methods has developed a competitive rather than cooperative spirit, the result too often being the playing off of one method against another-microbicides versus the female condom, for example. ${ }^{22}$ The allure of the unknown in future HIV prevention technology is presently holding us captive to a proprietary, pharmaceutical model of public health, rather than liberating us to mold something more creative, and above all, more ethically just. Simply put, by not adopting choice as our clarion call, we maintain a level of mediocrity in our practice as well as in our service to the women who are counting on us.

\section{Conclusions}

Women's heightened risk and vulnerability to HIV is multidimensional and lies in women's lower status worldwide. Most women around the world, including those in highrisk groups in the United States, are not usually protected by male condoms. Carrying through on our commitment to women's need for alternatives to the male condom means adopting the stance that for HIV prevention, something is better than nothing; providing women with options, even those with lower efficacy, is considerably better than offering none. Uniting now behind a choice platform-in research, policy and practice-and providing an adaptable framework to absorb new methods as they are developed and tested would prevent further waste of time. Finally, a choice platform is the prevention approach likely to make the greatest difference in reducing HIV incidence in women in the immediate future.

\section{REFERENCES}

1. Mantell JE et al., The promises and limitations of female-initiated methods of HIV/STI protection, Social Science $\&$ Medicine, 2006, 63(8): 1998-2009.

2. El-Bassel N et al., The efficacy of a relationship-based HIV/STD prevention program for heterosexual couples, American Journal of Public Health, 2003, 93(6):963-969; Kamb ML et al., Efficacy of risk-reduction counseling to prevent human immunodeficiency virus and sexually transmitted diseases: a randomized controlled trial, Journal of the American Medical Association, 1998, 280(13):1161-1167; Kwiatkowski CF et al., Predictors of increased condom use following HIV intervention with heterosexually active drug users, Drug and Alcohol Dependence, 1999, 54(1):57-62; Welsh MJ et al., Condom use during a community intervention trial in Kenya, International Journal of STD \& AIDS, 2001, 12(7):469-474; Feldblum PJ et al., Female condom introduction and sexually transmitted infection prevalence: results of a community intervention trial in Kenya, AIDS, 2001, 15(8):1037-1044; El-Bassel N and Schilling RF, 15-month followup of women methadone patients taught skills to reduce heterosexual HIV transmission, Public Health 
Reports, 1992, 107(5):500-504; Gollub EL et al., Dramatic impact on sexual risk behavior among active drug-using women: the BestBET study, paper presented at the annual meeting of the American Public Health Association, Washington, DC, Nov. 6-10, 2004; and Gollub EL et al., Achieving safer sex with choice: studying a women's sexual risk reduction hierarchy in an STD clinic, Journal of Women's Health E GenderBased Medicine, 2001, 10(8):771-783.

3. Hoffman S et al., The future of the female condom, International Family Planning Perspectives, 2004, 30(3):139-145.

4. Van Damme L et al., Effectiveness of COL-1492, a nonoxynol-9 vagi nal gel, on HIV-1 transmission in female sex workers: a randomised controlled trial, Lancet, 2002, 360(9338):971-977.

5. Moench TR, Chipato T and Padian NS, Preventing disease by protecting the cervix: the unexplored promise of internal vaginal barrier devices, AIDS, 2001, 15(13):1595-1602.

6. Cervical Barriers Advancement Society, MIRA: methods for improving reproductive health in Africa, February 2005, <http://www cervicalbarriers.org/documents/MIRAfactsheetv32.24.05.pdf>, accessed Sept. 30, 2006

7. Ramjee G and Ridzon R, Current non-vaccine HIV prevention trials and the challenges in conducting large Phase III efficacy trials, paper presented at the XVI International AIDS Conference, Toronto, Aug. $13-18,2006$

8. Foss AM et al., Shifts in condom use following microbicide introduction: should we be concerned? AIDS, 2003, 17(8):1227-1237; Foss AM, The importance of microbicide STI-efficacy in reducing HIV-risk: model projections, paper presented at the Microbicides 2006 conference, Cape Town, South Africa, Apr. 23-26, 2006; and Hoffman S, The female condom: acceptability and patterns of use, paper presented at the Global Consultation on the Female Condom conference, Baltimore, MD, USA, Sept. 26-29, 2005.

9. Des Jarlais DC et al., Reductions in hepatitis C virus and HIV infections among injecting drug users in New York City, 1990-2001, AIDS, 2005, 19(Suppl. 3):S20-S25.

10. Rosenberg MJ et al., Barrier contraceptives and sexually transmitted diseases in women: a comparison of female-dependent methods and condoms, American Journal of Public Health, 1992, 82(5):669-674 and Rosenberg MJ and Gollub EL, Methods women can use that may prevent sexually transmitted disease, including HIV, American Journal of Public Health, 1992, 82(11): 1473-1478.

11. Stein ZA, HIV prevention: the need for methods women can use, American Journal of Public Health, 1990, 80(4):460-462.

12. New York State Department of Health AIDS Institute, Methods of personal protection for women to reduce transmission of HIV through vaginal intercourse, policy statement, January 1992 and revision, 2000; and Gollub EL, Woman-controlled prevention techniques and technologies, in: O'Leary A and Jemmott LS, eds., Women at Risk: The Emerging Epidemic, New York: Plenum Press, 1995, pp. 43-82.

13. Gollub EL et al., 2001, op. cit. (see reference 2); Gollub EL, Stein Z and El-Sadr W, Short-term acceptability of the female condom among staff and patients at a New York City Hospital, Family Planning Perspectives, 1995, 27(4):155-158; Malow RM, Ziskind D and Jones DL, Use of female controlled microbicidal products for HIV risk reduction, AIDS Care, 2000, 12(5):581-588; Hadden BR, An HIV/AIDS prevention intervention with female and male STD patients in a peri- urban settlement in KwaZulu Natal, South Africa, International Center for Research on Women: Women and AIDS Research Program, Project Summary [conference version], 1997; Richardson BA et al., Evaluation of a low-dose nonoxynol-9 gel for the prevention of sexually transmitted diseases: a randomized clinical trial, Sexually Transmitted Diseases, 2001, 28(7):394-400; Steiner MJ et al., Increasing barrier method use among oral contraceptive users at risk of STDs: what approach is best? Sexually Transmitted Diseases, 1998, 25(3):139-143; Roddy RE et al., Effect of nonoxynol-9 gel on urogenital gonorrhea and chlamydial infection: a randomized controlled trial, Journal of the American Medical Association, 2002, 287(9):1117-1122; Roddy RE et al., A controlled trial of nonoxynol 9 to reduce male-to-female transmission of sexually transmitted diseases, New England Journal of Medicine, 1998, 339(8):504-510; and Stein Z et al., Safer sex strategies for women: the hierarchical model in methadone treatment clinics, Journal of Urban Health, 1999, 76(1): $62-72$.

14. Hamblin J and Reid E, Women, the HIV epidemic, and human rights: a tragic imperative, HIV and Development Programme Issues Paper No. 8, United Nations Development Programme, May 1991, <http:// www.undp.org/hiv/publications/issues/english/issue08e.htm>, accessed Nov. 29, 2006

15. Foss AM et al., 2003, op. cit. (see reference 8); Stein ZA, Do women leave the male condom when counseled in multiple options for protection? poster presented at the Microbicides 2006 conference, Cape Town, South Africa, Apr. 23-26, 2006; and Stein Z and Hoffman S, Misconceptions: condoms are for men, Yale Journal of Public Health, 2006, 3(3):7.

16. Stein ZA, 1990, op. cit. (see reference 11).

17. Gollub EL et al., 2001, op. cit. (see reference 2).

18. Mason T and Gollub EL, The body empowerment model: an approach to educating women, paper presented at the annual meeting of the Society for Applied Anthropology, Dallas, TX, USA, Mar. 31-Apr. 4, 2004 .

19. Latka M et al., Male-condom and female-condom use among women after counseling in a risk-reduction hierarchy for STD prevention, Sexually Transmitted Diseases, 2000, 27(8):431-437.

20. Susser I and Stein Z, Culture, sexuality, and women's agency in the prevention of HIV/AIDS in southern Africa, American Journal of Public Health, 2000, 90(7):1042-48; and Gollub E, Women's right to microbicides: conditional or unconditional? paper presented at the Microbicides 2004 conference, London, Mar. 28-31, 2004.

21. Rivers K et al., Gender relations, sexual communication, and the female condom, Critical Public Health, 1998, 8(4):273-290.

22. Gollub EL, Women's HIV/STD prevention methods: a call for unity, unpublished manuscript, University of Bordeaux, Bordeaux, France, 2005

\section{Acknowledgments}

This work was supported in part by the Female Health Company. The author wishes to thank Judy Sackoff, Zena Stein, Mitchell Warren and Kevin Whaley for their valuable comments on previous versions of this viewpoint.

Author contact: elgollub@aol.com 